\title{
EXPERIMENTAÇÃO CARTOGRÁFICA: RELATO DE EXPERIÊNCIA NOS CAMINHOS DA VISITA DOMICILIAR EM SAÚDE MENTAL
}

\section{CARTOGRAPHIC EXPERIMENTATION: EXPERIENCE REPORT ON THE PATHS OF HOME VISIT IN MENTAL HEALTH}

\author{
Luciana Cunha Paixão*, Lidiane de Fátima Barbosa Guedes** \\ Autora para correspondência: Luciana Cunha Paixão - cpaixaoluciana@gmail.com \\ *Estudante do Programa de Pós-graduação da Escola Bahiana de Medicina e Saúde Pública - Curso de \\ Especialização em Saúde Mental e Atenção Básica \\ **Mestre em Psicologia Social pela Universidade Federal de Sergipe. Docente da Escola Bahiana de \\ Medicina e Saúde Pública. Pesquisadora no Laboratório Interdisciplinar Cuidado e Saúde Mental - LICS
}

R E S U M O

\begin{abstract}
Este texto se constitui em um relato de experiência cujo objetivo é apresentar a cartografia de uma experiência de Visita Domiciliar em Saúde Mental vivenciada por uma enfermeira à época de sua formação acadêmica no curso de Enfermagem em uma Universidade. O método cartográfico, inspirado na filosofia da Diferença de Gilles Deleuze e Félix Guattari se configura na aposta metodológica adotada, no intuito de acompanhar a processualidade da experiência vivenciada e a produção de subjetividades. Descrição do caso: a experiência da visita domiciliar configurou atividade acadêmica vinculada a serviços de saúde do Sistema Único de Saúde num município do recôncavo baiano, experiência esta rememorada à luz da cartografia na conclusão de um curso de pós-graduação, quando reflexões, análises e (re)conhecimentos se somaram a experiência, renovando-a. Ao longo da construção do relato alguns conceitos como transversalidade, atenção, territorialização e rizoma, amplamente discutidos sob a ótica da cartografia, se apresentaram como caminhos na própria construção do método e modo de relatar a experiência, como sugere a proposta cartográfica. Concluindo que a experiência não acaba ao final do relato, alguns resultados podem ser destacados nesse mergulho da aprendiz de cartógrafa na experiência de cartografar, que the confere algumas surpresas como encontros, bem como obstáculos, rupturas, produção de conhecimentos e reconhecimentos, próprios de uma caminhada.
\end{abstract}

Palavras-chave: Visita domiciliar ; saúde mental; Sistema Único de Saúde. 
This text is about an experience report whose objective is to present the cartography of an experience of home visit in mental health experienced by a nurse at the time of her undergraduation as a Nursing major in the University. The cartography method inspired in the Difference Philosophy by Gilles Deleuze and Félix Guattari was the methodologic strategy chosen, in order to follow the processuality of the experience and the production of subjectivities. Case description: the experience of home visit was an academic activity associated to health services of Unified Health System at a town in the countryside of Bahia. The experience recollected by the cartography perspective during the postgraduate conclusion increases thoughts, analysis, recognitions and knowledge, creating a new experience at all. Along the construction report some concepts such as transversality, attention, territorialization and rhizome, largely discussed by the cartography perspective, appeared like ways on the method construction itself and mode to report the experience, as suggested by the cartography method. In conclusion that the experience doesn't finish by the end of the report, some results can be highlighted on this submersion of a cartographer undergoing formation that offers her some surprises as meetings, obstacles, breakthroughs, production of knowledge and recognitions, typical of a pathway.

Keywords: Home visit; mental health; Unified Health System. 


\section{INTRODUÇÃO: \\ ENTRANDO NA CARTOGRAFIA E ENCONTRANDO UM MÉTODO}

O presente relato de experiência constitui um ensaio cartográfico cujo pano de fundo é uma experiência resgatada pela memória. Objetivando acompanhála em sua processualidade emergem subjetividades, (re)conhecimentos, conceitos, encontros, obstáculos que apresentando-se ao longo dessa caminhada que é a escrita - também a compõe.

Foi levantando a temática proposta para Trabalho de Conclusão de Curso de Especialização, num convite para repensar a prática em Visita Domiciliar (VD) em saúde mental, na minha trajetória enquanto graduanda de enfermagem, que fui apresentada a cartografia como método de pesquisa. A cartografia é um método formulado por Deleuze e Guattari (1995) que visa acompanhar um processo, investigar um processo de produção'.

A prática da VD inspiradora desse relato compôs um projeto cujo um dos objetivos era reorientar a formação profissional através da experiência em áreas estratégicas do Sistema Único de Saúde (SUS). A área estratégica que compôs o meu território de prática foi o Centro de Atenção Psicossocial Álcool e outras Drogas (CAPS-AD) de um município do recôncavo baiano e a VD vinculada a esse serviço foi o recorte temático de referência do trabalho realizado.

Repensar a prática profissional/formativa é mais que buscar a lembrança de algo que fizemos. Implica, sobretudo, repensar a nós mesmos. Exercício que produz efeitos de deslocamentos, expressão de sentimentos que acompanharam a trajetória formativa.

Academicamente aprendemos a nos posicionar impessoalmente na escrita científica. Não importa aí o que se passa ao pesquisador, ao contrário, isso comprometeria a qualidade do trabalho2. Assim, revisitando meus diários de campo sobre as VD realizadas, algumas inquietações: 0 que fazer com a escrita que acompanha os sentimentos advindos deste movimento de repensar e revisitar uma experiência? O modelo hegemônico de escrita científica distanciava-se do relato encarnado numa vivência que fazia a escrita escapar, para dar expressão a subjetividades.

É inegável a importância do método científico tradicional e suas contribuições para a vida do homem, no entanto há de se incluir a subjetividade, que participando do pesquisar também produz conhecimentos.

A palavra repensar significa pensar de novo ${ }^{3}$, aqui apresenta $\circ$ sentido de produzir novo pensamento aproximando-se da cartografia, não pela representação do pensamento, mas ao sugerir um modo de acompanhar o engendramento desse pensamento, e, portanto acompanhar um processo ${ }^{2}$.

Rememorar essa experiência através da cartografia possibilita a atualização de processos. Permiteme senti-la novamente, dando atenção a outros aspectos da vivência. Posso ainda ressignificá-la, pois retomá-la a partir do que sou hoje é novo e único.

O método cartográfico propõe como direcionamento para a pesquisa-intervenção a reversão do método de pesquisar "não mais um caminhar para alcançar metas pré-fixadas (metá-hódos)", mas traçar no percurso, suas metas.

Nesse sentido,

"O caminho do cartógrafo se faz ao se caminhar, ao seguir e acompanhar os percursos e as implicações nos processos de produção e conexão de redes e rizomas. Foi no curso da caminhada e do caminho que se buscou traçar pistas que pudessem descrever, problematizar, discutir e, sobretudo, coletivizar a experiência e os sentidos produzidos pelo(a) cartógrafo(fia)" 5 .

A composição da pesquisa com o método cartográfico "não impede que se procurem estabelecer algumas pistas que têm em vista descrever, discutir e, sobretudo, coletivizar a experiência do cartógrafo"1. Inspirada nesta acepção, utilizamos como pistas cartográficas a expressão "caminhos" - pistas que funcionam como referências para aprendiz de cartógrafa imersa no território das VD e ao mesmo tempo rastreiam a "manutenção de uma atitude de abertura ao que vai se produzindo e de calibragem do caminhar no próprio percurso da pesquisa - o hódos-metá da pesquisa"2. 


\section{CONSTRUINDO MEU HÓDOS-METÁ}

\subsection{PELO CAMINHO DA TRANSVERSALIDADE E DA ATENÇÃO}

A experimentação do método cartográfico necessita da dissolução do ponto de vista do observador ${ }^{6}$. Há de se pensar na posição do cartógrafo frente uma experiência, ainda que siga pistas/caminhos, ele não deverá prender-se a um roteiro pré-estabelecido.

Assim, o conceito da transversalidade apresenta-se como "abertura do coeficiente comunicacional dos sujeitos e dos grupos". Não se trata de sobrepor a primeira pessoa a terceira pessoa, mas considerar nova pessoa que emerge do encontro delas. Neste sentido, o texto corrente apresenta-se em variações entre a primeira pessoa do singular (fazendo menção às situações vivenciadas pessoalmente no campo da pesquisa e por isso referenciada no diário de campo) e primeira pessoa do plural (enfatizando a produção coletiva do conhecimento). Dessa forma, a aprendiz de cartógrafa demarca uma posição ética, estética e política no processo de produção de conhecimentos.

O próprio conceito de transversalidade que permeia - leito da clínica ampliada na saúde, como abertura para possibilidades (diversas, multifacetadas, diferentes) nas práticas de saúde, parte de um novo lugar no qual todos os atores são também sujeitos implicados na construção de uma realidade. Sendo assim, não seria a própria transversalidade condição para que se alcance a integralidade das ações em saúde?

É pensando sobre como posso perceber a experiência e me deixar ser atravessada por ela que cruzo com as discussões sobre a atenção e sua função, que não deve ser seletiva, focalizada em representar as formas dos objetos, mas propensa a detectar forças circulantes, pontas do processo em curso'. Neste sentido, a atenção deverá estar em suspenso, sem focalização, propiciando captar-se o que está à disposição do observador (seu sistema de crenças, teorias, conhecimentos), mas também o que lhe está alheio, mas ali, pulsando no ambiente'.

Tratamos então de uma atenção que possa acolher - que nos é estranho, o inesperado, aberta, por assim dizer à descoberta.

Na prática da VD, alguns conceitos importantes chamam a atenção, como escuta significando "acolher toda queixa ou relato do usuário mesmo quando aparentemente não interessar diretamente para o diagnóstico e tratamento"7, acolhimento como aquilo que "estabelece o vínculo e permite - cuidado"8 e humanização "como uma política transversal, supõe necessariamente que sejam ultrapassadas as fronteiras, muitas vezes rígidas, dos diferentes núcleos de saber/poder que se ocupam da produção da saúde"".

Na abertura da atenção do cartógrafo que se lança num território, receptivo aos acontecimentos, até ser acometido por algo que exige atenção, direcionome aos registros dos diários de campo. Deparo-me com descrições de momentos em que os usuários dos serviços comentaram se sentir tristes, confusos, comentários aos quais eu respondia com sugestões/ imposições "Você deveria procurar a psicóloga do CAPS (AD)". "Você tem que conversar isso com a psicóloga da próxima vez que você for lá (CAPSAD)".

Atento agora que naquele momento eu não escutei, não acolhi, na tentativa de dar uma resposta encaminhei a demanda para outro profissional. Essas falas/faltas destacadas acima, que julguei nas condutas de outros profissionais, o que também faço agora comigo mesma, julgando as falas como faltas me mostra o quão presa estou a conceitos do que é certo e errado. Faz-se necessário compor essa análise do processo com o conceito de implicação.

A implicação entendida aqui fala menos à vontade e intenção (conscientes) dos sujeitos do que às forças (inconscientes) que se cruzam compondo valores, interesses, expectativas, ou seja, formas que se instituem como uma realidade. $\mathrm{Na}$ análise de implicação o que se faz é a quebra dessas formas instituídas visando à expressão do processo de institucionalização e permitindo a intervenção ${ }^{4}$. Logo, esse encontro inesperado com as falas caracteriza uma intervenção produtora do conhecimento (ou reconhecimento) de formas instituídas que se refletiram em minha prática na VD. A atenção ganha assim nova função, a de produzir algo novo e/ou perceber algo que ali já estava, uma potencialidade, uma virtualidade? 
Esse observador implicado, cujo olhar está dissolvendo-se e cuja atenção está abrindo-se e sensibilizando-se para receptividade se lança numa experiência, que é um lugar ocupado, um território a ser explorado, que por sua vez, já é habitado e continuamente se transforma independente do observador, sendo que na presença dele também será afetado num processo que não culminará com a passagem desse observador, trata-se, pois de um território vivo, em constante transformação.

\subsection{PELO CAMINHO DA TERRITORIALIZAÇÃO: APROPRIANDO-ME DO TERRITÓRIO}

O território das VD pertence a um município do recôncavo baiano, de clima chuvoso, famoso por suas tradições religiosas e força econômica no comércio (sobretudo a feira livre) ${ }^{10}$. Ao deixarse atravessar pelos acontecimentos do território, acompanhando sua dinâmica, interagindo com esse território e com o que dele emerge, compõem-se territórios existenciais ${ }^{11}$.

Entendendo que embora características territoriais confiram identidade ao município constituindo linhas que dão formas a ele, sendo notadas na circulação pelo território, como arranjos nas vidas das pessoas que nele existem, essas linhas não traduzem o todo do território, elas são tensionadas pelas forças que dele efluem, nele afluem e assim confluem.

Fazendo-se necessário apropriar-me de algum modo daquele território, um processo fora construído em grupo (estudantes de enfermagem, funcionária do CAPS-AD e professores da universidade):

1.Elencar os usuários a serem visitados primeiramente, estabelecendo como critério de inclusão aqueles absenteístas;

2. Estabelecer ponto de partida: num território tão vasto, com tantos usuários que atendiam ao critério de inclusão, por onde começaríamos? A resposta apresentou-se num obstáculo. Não dispúnhamos de carro para fazer as visitas, pois o carro que atendia às demandas do CAPS-AD, atendia também a outras demandas do município. Precisávamos então elencar as visitas que podíamos fazer a pé. Assim permanecemos nos arredores do CAPS-AD;

3. Construção de roteiro de VD com fundamentação teórica;

4. Contactação dos usuários para marcação das visitas.

A cartografia é o acompanhamento do traçado das linhas que compõem o plano em que a realidade toda se comunica "o que interessa é o que se passa entre os grupos, nos grupos, no que está para além e aquém da forma dos grupos, entre as formas ou no atravessamento delas". No plano dessas forças, chamam atenção certas lembranças, como o orgulho de um dos usuários do CAPS-AD que visitamos, ao mostrar seu trabalho com artesanato: a escolha dos materiais, a confecção, a venda do produto final... O mesmo que havia sido caracterizado pelos familiares, que por sua vez, presos a linhas molares se limitaram a contorná-lo, estigmatizá-lo como problemático. Problemático pelo uso de substâncias psicoativas (SPA); problemático por ter envolvido familiares nas dívidas com traficantes; problemático por já ter tido problemas com os vizinhos e a Justiça.

Neste processo de escrita sou afetada pelas marcas da lembrança de um encontro com outro usuário nos arredores da feira livre da cidade. Chovia quando busquei abrigo num estabelecimento, onde o vi. $O$ cumprimentei, ele olhou em volta, baixou as vistas e saiu na chuva, não respondeu. Em alguns dias o visitei novamente em casa e ele parecia envergonhado. Seria por não ter falado comigo num contexto outro que não da VD, que por sua vez remetia (e assim também eu a representava) a uma situação de saúde usualmente estigmatizada, como o é a relação com SPA? O fato é que nesse dia não conversou como das outras vezes, seus pais deram o curso da conversa, ele mesmo não me olhou nos olhos. Passamos a visita assim: eu buscando seu olhar quando ele falava, e ele se desviando das minhas investidas. Demonstrase assim a inter-relação dos eventos num território intervindo diretamente nas suas linhas. No caso enrijeceu-se o processo realçando-se a linha molar da relação institucionalizada.

Em outra cena, conheci Onofre (nome fictício). Na primeira visita seu irmão nos recebeu despejando em nós, assim que entramos, a dependência de álcool de Onofre e como a relação deste com a substância tinha interferido na sua saúde e autocuidado, na sua relação com familiares. Onofre já não mais trabalhava, não comia, "a comida fica aí, 
de dar bicho" (apontava o irmão), ele só bebia...

Fomos levadas ao encontro de Onofre que receoso disse estar nos esperando. Senti o cheiro forte do álcool no quarto abafado, fiquei tonta. Apresentamos-nos, conversamos um pouco "como o senhor tem passado seu Onofre?". Ele falou sobre ser diabético, mostrou suas medicações (estragadas, embalagens violadas). Enquanto conversávamos sobre o que Onofre trazia como assunto, o conflito com seu irmão reverberava no quarto. Na tentativa de mostrar que se cuidava de algum modo mostrando requisições de exames a fazer - era desmentido pelo irmão.

Seu irmão o interrompeu mencionando que a casa não estava "arrumada" daquele jeito, sempre tinha restos de comida em decomposição pelo chão, os vômitos se acumulavam. A casa só estava limpa porque faríamos a visita. Onofre falou que "sentia vergonha da casa daquele jeito", tinha limpado a casa para nos receber. Um movimento de Onofre seguia na contracorrente da vida estigmatizada na relação com a bebida. Uma possível linha de fuga emergiria naquele momento?Lembro-me de ter ficado constrangida, me dando conta de estar presenciando e agora vejo que estava também participando da intimidade de alguém.

Ao final daquela visita Onofre concordou que marcássemos - pois ele alegava nunca conseguir uma consulta na Unidade de Saúde da Família (USF), pelo diabetes, medicações, requisições de exames vencidas. Sobre o diabetes ele queria conversar, fez perguntas, pediu orientações.

$\mathrm{Na}$ despedida Onofre perguntou quando voltaríamos, queria contar sobre a consulta, contar que estaria melhor.

Seguimos direto à USF, conversamos com a enfermeira - ciente de nossas atividades - que outrora se disponibilizou a encaixar os usuários do CAPS-AD no atendimento conforme a disponibilidade deles, a despeito da agenda da unidade, dentro do possível. Precisávamos dessa flexibilidade, era uma forma de manter a porta do serviço aberta para os usuários que não costumavam buscar aquele atendimento.

Alguma coisa acontecera no quarto de Onofre. Ele aceitou nos receber, limpou a casa por isso, conversou conosco, pediu que voltássemos. Uma porta se abria. Passando por ela, quem sabe um dia, Onofre quisesse conversar sobre outros aspectos de sua vida? Mas essa era uma projeção minha: "talvez ele volte ao CAPS-AD". Onofre morreu antes de fazermos a segunda visita.

Ficamos muito tristes - minha colega e eu - quando recebemos a notícia chegando ao CAPS-AD antes de mais uma tarde de visita. Conversamos com a funcionária que prestou socorro a Onofre. Entristecida, comentou sentir impotência e frustração sobre o trabalho desenvolvido no CAPS-AD nesses momentos. Mencionou lembrar-se de apenas um caso que considerava êxito no processo terapêutico - um senhor que permanecia em abstinência há alguns anos. Aquilo me chamou atenção na época, registrei no meu diário de campo.

O êxito atribuído à abstinência, uma das características do modelo proibicionista focado na propriedade farmacológica das drogas, na ilegalidade das mesmas, bem como na repressão ao uso e ao usuário ${ }^{12}$, evidencia a supremacia desta ideia como única alternativa possível na relação com SPA, ao ainda apresentar-se na fala de trabalhadores de um serviço suposto a reorientar a assistência.

Tal lacuna entre política e prática também encontra lugar na cartografia, podendo "ser entendida como um método segundo o qual toda pesquisa tem uma direção clínico-política e toda a prática clínica é, por sua vez, intervenção geradora de conhecimento" 4 . Portanto, a transformação daquele que vivencia algo é a energia propulsora à transformação de sua prática, alinhando-se aí a uma política.

\subsection{PELO CAMINHO DAS ARTICULAÇÕES DA REDE RIZOMÁTICA}

Fruto das reflexões de Deleuze e Guattari, rizoma é entendido como uma formação sem entradas nem saídas, que engloba como princípios a conexão e a heterogeneidade, pelas quais um ponto pode ser conectado a qualquer outro. Inclui ainda a multiplicidade, contando com mudança de natureza à medida que se aumentam as conexões, e articulando-se à noção de ruptura, a partir da qual um rizoma pode ser rompido ou retomado em qualquer lugar ${ }^{13,14}$. 
Comparando rizomas e redes de atenção à saúde, como conjunto de ações e serviços articulados para garantir a integralidade da assistência ${ }^{15}$, são essas articulações, as conexões necessárias a tecitura e entrelaçamento da rede, figurada nos dispositivos de saúde, contudo, movimentada pelas pessoas que nesses dispositivos operam, expandindo a rede, produzindo conflitos, linhas de fuga (pontas do processo em curso, linhas criadoras) ${ }^{1,4}$, subjetividades $^{13}$.

Um desdobramento das VD foi a necessidade de articulação entre CAPS-AD e USF do território. Essa articulação é conceituada politicamente como matriciamento, modo compartilhado de produzir saúde, onde equipes de saúde "criam uma proposta de intervenção pedagógico-terapêutica". . Assim a importância dos Agentes Comunitários de Saúde (ACS) nas VD aos usuários do CAPS-AD começou a ser trabalhada numa sequência de reuniões.

As dificuldades enumeradas para a realização das visitas eram muitas, mas sobressaltavam-se a falta de capacitação relativa às SPA e a periculosidade relacionada às situações de tráfico. Diante disso, os debates focaram na sensibilização sobre o vínculo do usuário com a USF, acesso à saúde como direito, além do fortalecimento da imagem do ACS como membro da equipe de saúde. A proposta de mudança de abordagem aos usuários, às demandas outras de saúde, não reduzidas somente às questões sobre o uso de SPA, surgiu como estratégia inicial para transformação das VD.

Ciente de que não esvaziamos a discussão nem radicalizamos a prática das VD naquele serviço, ao levantarmos possibilidades não estaríamos também contribuindo com a produção de novos fazeres?

\section{ENSAIANDO UM DESFECHO: UMA RUPTURA NO CAMINHO}

Através da escrita cartográfica deparei-me com virtualidades, sensações já conhecidas, sensações novas, testemunhei a produção de subjetividades, em certa medida me constituí nesse caminho.
Indubitavelmente na tentativa de cartografar, acabei não cartografando em várias linhas desse relato, como também não tenho dúvidas de que fui tocada pela potência que vibra na cartografia em outras linhas.

Quanto às rupturas e obstáculos do caminho, esses constituem também potencialidades, "abertura de linhas de fuga para outros sentidos, não previstos anteriormente, o que tem como significado uma alta capacidade de produzir-se a si mesmo, algo próprio das redes rizomáticas"14. Atentando para nova ruptura que se faz agora (a pausa nessa escrita), peço uma última licença para desconstruir expectativa criada inicialmente nesse mergulho: atribuí à cartografia a possibilidade de repensar minha prática, essa moralidade que a conferi como solução para inquietações prévias, não comunica com a potência do acompanhamento de processualidades.

Permito-me, contudo, alimentar a necessidade de afinar minha atenção para os devires de acompanhamentos, cartografias futuras, em linhas de fuga que hão de se apresentar na minha caminhada pela enfermagem, seja na relação com outros aos quais vou assistir ou com os quais vou prestar assistência.

\section{REFERÊNCIAS}

1. Kastrup V. O funcionamento da atenção no trabalho do cartógrafo. In: Passos E, Kastrup V, Escóssia L, organizadores. Pistas do método da cartografia: Pesquisa-intervenção e produção de subjetividade. Porto Alegre: Sulina; 2009. P. 32-51

2. Passos E, Kastrup V, Escóssia L. Pistas do método da cartografia: Pesquisa-intervenção e produção de subjetividade. Porto Alegre: Sulina; 2009. P. 207

3. Ferreira $A B H$. Novo Dicionário da Língua Portuguesa. $5^{a}$ ed. Rio de Janeiro: Positivo; 2010

4. Passos E, Barros RB. A cartografia como método de pesquisa-intervenção. In: Passos E, Kastrup V, Escóssia L, organizadores. Pistas do método da cartografia: Pesquisa-intervenção e produção de subjetividade. Porto Alegre: Sulina; 2009. P. 17-31 
5. Guedes LFB. Encontros de olhares: ensaiando carto(foto)grafias com usuários de drogas [Dissertação]. São Cristóvão: Núcleo de Pós-graduação e Pesquisa em Psicologia Social, Universidade Federal de Sergipe; 2014

6. Passos E, Eirado A. Cartografia como dissolução do ponto de vista do observador. In: Passos E, Kastrup V, Escóssia L. Pistas do método da cartografia: Pesquisaintervenção e produção de subjetividade. Porto Alegre: Sulina; 2009. P. 109-29

7. Brasil. Ministério da Saúde. Clínica ampliada e compartilhada. Secretaria de Atenção à Saúde. Política Nacional de Humanização da Atenção e Gestão do SUS. Série B. Textos Básicos de Saúde. Brasília. DF. 2009

8. Brasil. Ministério da Saúde. Guia prático de matriciamento em saúde mental. Centro de estudo e pesquisa em saúde coletiva. Brasília. DF. 2011

9. Brasil. Ministério da Saúde. HumanizaSUS: Política Nacional de Humanização: a humanização como eixo norteador das práticas de atenção e gestão em todas as instâncias do SUS. (Série B. Textos Básicos de Saúde). Brasília. DF. 2004

10. Araujo S, Coutinho S. O município de Santo Antonio de Jesus no Recôncavo Baiano [Internet]. 2016 [Atualizado 2016; citado 2016 jul. 1]. Disponível em: http://www.vertentes.ufba.br/o-municipio-de-santoantonio-de-jesus-no-reconcavo-baiano

11. Alvarez J, Passos E. Cartografar é habitar um território existencial. In: Passos E, Kastrup V, Escóssia L, organizadores. Pistas do método da cartografia: Pesquisa-intervenção e produção de subjetividade. Porto Alegre: Sulina; 2009. P. 131-49

12. Martins J, MacRae E. Por um olhar sociocultural sobre a questão das drogas. In: Nery Filho A, Valério ALR et al. Brasília: SENAD. Módulo para capacitação dos profissionais do projeto consultório de rua. Salvador: CETAD; 2010. P. 89

13. Dal Molin F. Rizomas e fluxos molares e moleculares da máquina-escola: confissões de um cartógrafo. Psicol. Soc. 2011 ;23(2):303-11. doi: 10.1590/S010271822011000200011

14. Carvalho MN, Franco TB. Cartografia dos caminhos de um usuário de serviços de saúde mental: produção de si e da cidade para desinstitucionalizar. Physis. 2015;25(3):863-84. doi: 10.1590/S0103-

\section{0}

15. Brasil. Ministério da Saúde. Política Nacional de Atenção Básica. Portaria n. 2.488, de 21 de outubro de 2011 . Aprova a Política Nacional de Atenção Básica, estabelecendo a revisão de diretrizes e normas para a organização da Atenção Básica, para a Estratégia Saúde da Família (ESF) e o Programa de Agentes Comunitários de Saúde (PACS). Brasília. DF; 2011 